\title{
Positive end-expiratory pressure selection by comprehensively considering clinical measurements and patient characteristics may improve ICU outcome in ARDS patients: an observational study
}

Huiqing Ge ( $\square$ gehq@zju.edu.cn )

Sir Run Run Shaw Hospital of Zhejiang University

\section{Qing Pan}

Zhejiang University of Technology

\section{Yuhan Zhou}

Zhejiang University of Technology

\section{Yilin Qian}

Zhejiang University of Technology

\section{Zhongheng Zhang}

Sir Run Run Shaw Hospital of Zhejiang University

\section{Luping Fang}

Zhejiang University of Technology

Gangmin Ning

Zhejiang University

\section{Leo M. Heunks}

Erasmus Medical Center

\section{Research Article}

Keywords: positive end-expiratory pressure, reinforcement learning, mechanical ventilation, intensive care unit

Posted Date: February 7th, 2022

DOI: https://doi.org/10.21203/rs.3.rs-1322548/v1

License: (c) (1) This work is licensed under a Creative Commons Attribution 4.0 International License.

Read Full License 


\title{
Positive end-expiratory pressure selection by
}

\section{comprehensively considering clinical measurements and \\ patient characteristics may improve ICU outcome in ARDS \\ patients: an observational study}

\author{
Qing Pan ${ }^{1 *}$, Yuhan Zhou ${ }^{1}$, Yilin Qian ${ }^{1}$, Zhongheng Zhang ${ }^{2}$, \\ Luping Fang ${ }^{1}$, Gangmin Ning ${ }^{3}$, Leo M. Heunks ${ }^{4}$, Huiqing $\mathrm{Ge}^{5^{*}}$
}

1. College of Information Engineering, Zhejiang University of Technology, Liuhe Rd. 288, Hangzhou 310023, China

2. Department of Emergency Medicine, Sir Run Run Shaw Hospital, School of Medicine, Zhejiang University, Qingchun East Rd. 3, Hangzhou 310016, China

3. Department of Biomedical Engineering, Zhejiang University, Zheda Rd. 38, Hangzhou 310027, China

4. Department of Intensive Care Medicine, Erasmus Medical Center, Dr. Molewaterplein 40, 3015 GD Rotterdam, the Netherlands

5. Department of Respiratory Care, Regional Medical Center for National Institute of Respiratory Diseases, Sir Run Run Shaw Hospital, School of Medicine, Zhejiang University, Qingchun East Rd. 3, Hangzhou 310016, China

Corresponding authors:

Dr. Huiqing Ge

Department of Respiratory Care, Sir Run Run Shaw Hospital of Zhejiang University,

Qingchun East Rd. 3, Hangzhou 310016, China

Tel: +86-571-86006855

Email: gehq@zju.edu.cn

Dr. Qing Pan

College of Information Engineering, Zhejiang University of Technology, Liuhe Rd. 288, 310023 Hangzhou, China

Tel: +86-571-85290595

Email: pqpq@zjut.edu.cn 


\section{Abstract}

Background: It remains controversial as how to set positive end-expiratory pressure (PEEP) for acute respiratory distress syndrome (ARDS) patients. This study aims to provide suggestions to the clinicians in selecting PEEP for ARDS patients receiving invasive mechanical ventilation based on artificial intelligence (AI).

Methods: Invasively ventilated ARDS patients in MIMIC-IV and eICU databases were enrolled in the observational cohort study. An Al model trained by awarding survival for suggesting optimal PEEP was developed and tested on the MIMIC-IV database and externally validated on the elCU database. Three subgroups were defined in which the PEEP grades set by the Al model are lower, equal, and higher than that set by the clinicians (denoted as $\triangle P E E P<0, \triangle P E E P=0$, and $\triangle P E E P>0$, respectively). Intensive care unit (ICU) mortality and 28-day ventilation-free days are the primary and secondary outcomes.

Results: 6839 (MIMIC-IV) and 2117 (eICU) ARDS admissions were included in the study. The ICU mortalities are $10.8 \%$ and $8.6 \%$ in the $\triangle P E E P=0$ subgroup in the MIMIC-IV and eICU databases, respectively, and become higher in the $\triangle P E E P<0$ and $\triangle P E E P>0$ subgroups (MIMIC-IV: $25.6 \%$ and $23.7 \%$, eICU: $26.9 \%$ and $27.6 \%$ ). An explainable analysis reflects that the clinicians' PEEP setting relates more to the oxygenation, respiratory mechanics, and ventilatory settings, while the RL model also pays attention to the more comprehensive parameters concerning patient characteristics such as Sequential Organ Failure Assessment (SOFA) and age.

Conclusions: Al-based PEEP selection tends to consider clinical measurements and 
patient characteristics comprehensively, and is promising to improve the ICU outcomes for ARDS patients.

Keywords: positive end-expiratory pressure, reinforcement learning, mechanical ventilation, intensive care unit 


\section{Introduction}

The mortality of acute respiratory distress syndrome (ARDS) remains high despite the extensive research in the past 50 years since its first description [1]. Positive endexpiratory pressure (PEEP) plays a crucial role in the management of ARDS in a "double-edged sword" way. PEEP is applied to open the collapsed alveoli to improve arterial oxygenation, to reduce cyclic opening and closing of alveoli to mitigate atelectrauma, and to promote more homogeneous ventilation to reduce the stress at the margins between aerated and collapsed lung tissue [2]. However, excessive PEEP may contribute to the development of ventilator-induced lung injury (VILI) by alveolar overdistention [3].

PEEP titration is often used to select the optimal PEEP level. The currently used approaches for PEEP titration include those guided by clinical measurements, including $\mathrm{FiO}_{2}$ [4], arterial oxygenation [5], electrical imaging tomography [6], respiratory compliance [7, 8], and esophageal pressure [9-11]. Although most of the PEEP titration approaches can improve the oxygenation and/or respiratory mechanics, several large-scale clinical trials produce controversial conclusions regarding its effect on the clinical outcomes $[4,9,10,12,13]$. One of the major reasons for the controversy may be that ARDS is not a distinct disease but a heterogeneous syndrome [14]. Therefore, PEEP selection solely based on clinical measurement may be unable to provide optimal clinical outcome.

Artificial intelligence may shed a light on this question due to its ability in comprehensive knowledge discovery from a large amount of multi-modal medical data 
[15]. Reinforcement learning ( $R L)$, a branch of artificial intelligence, is capable of processing temporal dynamic data for decisions in an intensive care unit (ICU) [16]. The key feature of $\mathrm{RL}$ is that a computational model learns from human actions to achieve the best outcomes. It has been successfully applied to learn the optimal dosage of medication and volume therapy for sepsis patients [17] and select the optimal parameters for mechanical ventilation [18]. In the current study, we aimed to develop an RL-based model aiming to award survival to provide personalized suggestions to the clinicians in selecting PEEP for ARDS patients, and to explore the factors that the RL model considers in PEEP selection.

\section{Methods}

\section{Study Population}

The RL model was built based on the publicly available Medical Information Mart for Intensive Care IV (MIMIC-IV) database [19] and externally validated on the eICU Collaborative Research Database v2.0 (eICU) [20]. MIMIC-IV contains 69,619 distinct ICU stays of patients admitted to 11 ICUs at the Beth Israel Deaconess Medical Center in Boston, Massachusetts from 2008 to 2019 [19]. The elCU database contains 200,859 ICU stays for 139,367 distinct patients from 335 ICUs from 208 hospitals in the United States between 2014 and 2015 [20].

We include invasively ventilated ARDS patients in this study. The following inclusion criteria were applied to both databases: (1) age 18 years or older; receiving invasive mechanical ventilation for at least 24 consecutive hours; (3) diagnosed 
with ARDS, defined as the manifestation of a $\mathrm{PaO}_{2} / \mathrm{FiO} 2(\mathrm{P} / \mathrm{F})$ ratio lower than 300 $\mathrm{mmHg}$ within the first week from the start of mechanical ventilation (MV) [21], and have common risk factors for ARDS [22] (direct risk factors: pneumonia, aspiration of gastric contents, pulmonary contusion, inhalation injury, and near-drowning; indirect risk factors: sepsis, nonthoracic trauma or hemorrhagic shock, pancreatitis, major burn injury and drug overdose). Diagnosis of heart failure and pulmonary edema were excluded to rule out cardiogenic pulmonary edema. We randomly split the MIMIC-IV database into two parts, $80 \%$ for model development and $20 \%$ for model test. In addition, to verify the generalizing ability of our model, we tested our model on the elCU, a completely independent dataset.

Due to the retrospective design of the study, the ethical approval from the institutional review board is exempted. The data in both databases have been deidentified for research purposes.

\section{Model development}

The $\mathrm{RL}$ model is about a computational model adjusting PEEP in response to the changing states (clinical variables) of the patients to achieve an optimal reward. It is based on the estimation of the $Q$ functions $\hat{Q}(s, a)$, which provides the expected return of taking an action $a$ (adjustment of PEEP) at each state $s$ (a set of clinical variables). The Q-values are updated using the Bellman recursion $Q\left(s_{t}, a_{t}\right)=r_{t+1}+$ $\gamma\left(\max _{a^{\prime} \in A} \hat{Q}\left(s_{t+1}, a^{\prime}\right)\right)$, where $\gamma$ is the discount factor and gives the relative weight of the current and future return and $r_{t+1}$ is the instant reward at time $t+1$. We used a deep 
Q network (DQN) [23], which approximates $\hat{Q}(s, a)$ using deep neural networks by sampling and minimizing the squared error loss between the output and target $Q$ values, to learn the optimal PEEP policies. The approximated optimal policy after $\mathrm{N}$ iterations is given as $\pi^{*}(s)=\operatorname{argmax}\left(\hat{Q}_{N}(\mathrm{~s}, \mathrm{a})\right)$. The diagram of the DQN model is shown in eFigure 1.

A set of 25 variables were extracted from the databases, including demographics, clinical scores, vital signs, laboratory values, and ventilator parameters (eTable 1). They were collected during the whole ventilation period at 1-hour intervals. Variables with multiple measurements within a 1-hour interval were averaged. To address the problem of missing or irregularly sampled data, we adopted sample-and-hold to impute ventilator parameters and linear interpolation to impute laboratory values and vital signs. As for atemporal variables, their respective means of the dataset were imputed.

The action space includes 11 grades of PEEP, with $<5 \mathrm{cmH}_{2} \mathrm{O}$ and $\geq 23 \mathrm{cmH}_{2} \mathrm{O}$ the first and the last grade, and $2 \mathrm{cmH}_{2} \mathrm{O}$ the interval between consecutive grades (eTable 2). The grade is denoted as PEEP-G to distinguish it from the actual PEEP value. Given a PEEP-G, the actual PEEP range is between $5+($ PEEP-G -1$) \times 2$ and $5+$ PEEP-G $\times 2 \mathrm{cmH}_{2} \mathrm{O}$. The ICU survival was designated as the reward. A positive reward $(+100)$ would be given at every state if the patient finally survives. A negative time-dependent reward $-100 \times e^{t-t_{\text {end }}}$ was given to the dead subjects, where $t$ is the time of the current state and $t_{\text {end }}$ is the time of death. It is based on the consideration that the clinical variables closer to the time of death may have a stronger association with the outcome. 


\section{Clinical outcome}

The primary outcome was the ICU mortality rate. The secondary outcome was the 28day ventilation-free days.

\section{Data analysis}

Only the variables in the first week of MV using assist/control ventilation mode were involved in the model development and validation. For each patient, the difference between the PEEP grades ( $P E E P-G)$ given by the $\mathrm{RL}$ model and the clinicians was defined as

$$
\triangle P E E P-G=\frac{\sum_{s=1}^{N_{s}}\left(P E E P-G_{R L}(s)-P E E P-G_{c l i}(s)\right)}{N_{s}}
$$

where $s$ indicates the states and $N_{s}$ indicates the number of states for the investigated patient. In this study, each state means each hour.

Three subgroups were defined according to $\triangle P E E P-G>0, \triangle P E E P-G=0$, and $\triangle P E E P-G<0$, respectively. Furthermore, five ranges of $\triangle P E E P-G$ were defined with an interval of 1.0 PEEP grade (corresponding to $\sim 2 \mathrm{cmH}_{2} \mathrm{O}$ ) between neighboring ranges to assess the dependence of ICU mortality, 28-day ventilation-free days, and clinical variables on the $\triangle P E E P-G$. Changes in clinical variables with the variation of $\triangle P E E P-G$ were assessed using one-way ANOVA. An XGBoost classifier [24] was used to evaluate the feature importance in recommending high PEEP $\left(\geq 10 \mathrm{cmH}_{2} \mathrm{O}\right)$ and low PEEP $\left(<10 \mathrm{cmH}_{2} \mathrm{O}\right)$ for the clinicians and the $\mathrm{RL}$ model, respectively, to explain their actions. The reinforcement learning model, the XGBoost classifier, and all the statistical analyses were implemented using Python 3.8 and Scikit-learn package. 


\section{Results}

\section{Participants}

We extracted 6839 (MIMIC-IV) and 2117 (elCU) ARDS admissions, respectively. They were further categorized into mild $(200 \sim 300 \mathrm{mmHg})$, moderate $(100 \sim 200 \mathrm{mmHg})$, and severe $(<100 \mathrm{mmHg}$ ) ARDS severities according to their lowest P/F ratio in the first week of MV while in controlled mode (Figure 1). Patient demographics and clinical characteristics are shown in Table 1. The mortality of ARDS was 22.8\% (1560/6839) and $24.8 \%(524 / 2117)$ for the MIMIC-IV and elCU databases, respectively. The P/F ratio in MIMIC-IV was higher than that in eICU $(261.4 \pm 115.4$ vs. $229.9 \pm 120.8 \mathrm{mmHg}$, $p<0.001)$, while the given PEEP in eICU was lower than that in MIMIC-IV $(6.9 \pm 3.0$ vs. $\left.7.7 \pm 3.6 \mathrm{cmH}_{2} \mathrm{O}, \mathrm{p}<0.001\right)$.

\section{Optimal PEEP recommended by RL model}

In the MIMIC-IV database, the percentage of patients where the clinicians gave higher PEEP compared to the RL model is $52.0 \%$ and is higher for the more severe patients (severe: $75.9 \%$, moderate: $53.4 \%$, mild: $28.8 \%$, Table 2). The PEEP grades recommended by the $\mathrm{RL}$ model and set by the clinicians are $1.6 \pm 0.7$ and $2.9 \pm 1.4$, respectively $(p<0.001)$. The percentage of patients with direct ARDS risk factors is higher than those with indirect ARDS risk factors (direct: $58.8 \%$ vs. indirect: $41.2 \%$ ).

The percentages of patients where the clinicians gave lower PEEP compared to the RL model are close for all the three severities of disease (between $21.6 \%$ and $25.4 \%$ for the MIMIC-IV database). The PEEP grades recommended by the RL model and 
set by the clinicians are $2.4 \pm 0.7$ and $1.5 \pm 0.6$, respectively $(p<0.001)$. These patients are significantly younger than the other two subgroups (Table 2).

For the patients who were given equal PEEP by the $\mathrm{RL}$ and the clinicians, the PEEP grades are close to 1 (corresponding to $5 \sim 7 \mathrm{cmH}_{2} \mathrm{O}$ ). A major percentage of these patients are associated with indirect ARDS risk factors (direct: $42.5 \%$ vs. indirect: $57.4 \%)$

The ICU mortality was higher and the 28-day ventilation-free days was lower when $\triangle P E E P-G$ does not equal to zero (Table 2). For the $\triangle P E E P-G<0$ subgroup, with the decrease of $\triangle P E E P-G, I C U$ mortality increases, and the 28-day ventilation-free days decreases (Table 3). The increase in ICU mortality with the decrease of $\triangle P E E P-G$ was more evident in the moderate and severe ARDS and was strongly associated with worsening oxygenation, increased $\mathrm{FiO}_{2}$, body mass index (BMI), mechanical power (MP), and MP normalized to predicted body weight (norMP), but weakly with tidal volume, driving pressure (DP), and respiratory compliance (Table 3). When $\triangle P E E P-G$ equals zero, the patients have the lowest ICU mortality and the longest 28-day ventilation-free days (Table 2).

The XGBoost model which classifies the high $\left(\geq 10 \mathrm{cmH}_{2} \mathrm{O}\right)$ and low $\left(<10 \mathrm{cmH}_{2} \mathrm{O}\right)$ PEEP recommendations suggests that $\mathrm{FiO}_{2}$ and $\mathrm{RR}_{\text {set }}$ were the most important features for the recommendation of both the clinicians and the RL model (Figure 2). While the clinicians also considered some clinical observations, such as $\mathrm{SpO}_{2}, \mathrm{PaCO}_{2}$, $\mathrm{BMI}, \mathrm{DP}$, and P/F ratio, the RL model gave SOFA and demographics (age, BMI) a high priority. 
Similar findings are observed in the external validation on the eICU database. The increase in $\triangle P E E P-G$ also associated with increased ICU mortality and decreased 28-day ventilation-free days (eTable 4 and eFigure 2).

\section{Discussion}

The main findings of this study can be summarized as follows. First, the ICU mortality was higher when the clinicians' PEEP setting deviated from that of the RL model. Second, the performance of the RL model was associated with the severity of ARDS. For the severe ARDS in MIMIC-IV, the percentage of patients that recommended by lower, equal, and higher PEEP by the RL model were $75.9 \%, 2.4 \%$, and $21.6 \%$, respectively, whereas the percentages were $28.8 \%, 45.8 \%$, and $25.4 \%$ for the mild ARDS, respectively. Third, for the $\triangle P E E P-G<0$ subgroup, the decrease in the $\triangle P E E P-G$ was associated with an increase in the mortality rate and a decrease in 28day ventilation-free days, while the tidal volume, driving pressure, and respiratory compliance did not differ significantly. Fourth, despite that the PEEP setting is related to $\mathrm{FiO}_{2}, \mathrm{RR}_{\text {set, }}$ and $\mathrm{BMI}$ for both the clinicians and the $\mathrm{RL}$ model, it is found that the PEEP setting by the clinicians is more related to the clinical measurements such as $\mathrm{P} / \mathrm{F}, \mathrm{DP}, \mathrm{SpO}_{2}$, and $\mathrm{PaCO}_{2}$, while the $\mathrm{RL}$ model puts focus on the SOFA score and age, which may convey more comprehensive information about the characteristics of patients.

The RL model gave equal PEEP compared with the clinicians for $21.4 \%$ subjects in MIMIC-IV and 15.4\% subjects in eICU. Most of these patients are mild and moderate 
ARDS and have the lowest percentage with direct ARDS risk factors. They show relatively low mortality and long 28-day ventilation-free days. The PEEP grades recommended by either the clinicians or the $\mathrm{RL}$ model were both close to grade 1.0, corresponding to $5 \sim 7 \mathrm{cmH}_{2} \mathrm{O}$. It suggests that the $\mathrm{RL}$ model can replicate the clinicians' knowledge to set appropriate PEEP for the ARDS patients who do not need high PEEP to prevent overdistension-induced VILI [25].

The $\mathrm{RL}$ model gave lower PEEP in comparison to the clinicians in $52.0 \%$ of patients in MIMIC-IV and $34.2 \%$ of patients in eICU. The association of ICU mortality for the moderate to severe ARDS with $\triangle P E E P-G$ (Table 3 and eTable 4) indicates that for the patients with higher ICU mortality, the PEEP settings made by awarding survival using the RL model were likely to deviate stronger from that of the clinicians. We suggest that in these patients, setting higher PEEP did not further improve respiratory mechanics, but further increase $\mathrm{P}_{\text {plat, }} \mathrm{MP}$, and norMP (Table 3), resulting in stronger degrees of lung injury [26] and thus poorer outcomes. On the contrary, the $\triangle P E E P-\mathrm{G}>0$ subgroup is significantly younger, has a better SOFA score, and better $\mathrm{P} / \mathrm{F}$ than the $\triangle P E E P-\mathrm{G}<0$ subgroup. And the percentages of these patients in the mild, moderate, and severe groups are close.

More and more evidence shows the importance of the biological and clinical heterogeneity of ARDS on the selection of ventilatory strategy [14]. Sub-phenotypes of ARDS characterized by inflammatory biomarkers respond differently to PEEP [27]. The ARDS respiratory support statement issued by ATS, SCCM, and ESICM in 2017 conditionally recommended a higher level of PEEP for adult patients with moderate or 
severe ARDS [28] and pointed out the importance to recognize the patients who are most likely to benefit from higher PEEP. In the investigated cohorts, the analysis of feature importance for classifying high PEEP and low PEEP (Figure 2(a)) shows that the PEEP setting by the clinicians is more related to the well-established targets such as oxygenation [5], respiratory mechanics [7, 8], and also BMI [29]. By contrast, in addition to the $\mathrm{FiO}_{2}$, the $\mathrm{RL}$ model was more inclined to consider the SOFA score (and age), which may convey more comprehensive information regarding patient characteristics, exhibit a high rank of feature importance. The driving pressure of these patients was not found to be strongly associated with the PEEP selection decision for the RL model, probably because they were well controlled in the investigated cohorts [30].

The study has several limitations. First, it should be noticed that the RL model's recommendations do not result in real clinical actions in the study due to the retrospective observational design of the study. It is therefore an "off-line" reinforcement learning process. Even so, the results could be interpreted in the way that the outcome was worse if the clinicians' decisions deviate from that of the RL model. Second, the chest X-ray imaging required for defining ARDS according to the Berlin definition is missing. In addition, the Berlin definition itself is also criticized in some cases [31]. We included the patients who have the common risk factors for ARDS [22] to make the cohort as suitable as possible for the aim of this study. In the future, more strict recruitment of subjects should be conducted to validate the effectiveness of the RL model. Third, it is unknown what approaches were adopted to titrate PEEP 
in the investigated cohort, or whether a recruitment maneuver was performed, preventing us from an in-depth analysis of the association between $\triangle P E E P$ and the titrating approaches.

\section{Conclusion}

In conclusion, the RL model aiming to award survival succeeds in recommending personalized PEEP for ARDS patients and is promising to improve the clinical outcome. Further prospective studies are needed to confirm whether the RL-based PEEP setting strategy can assist the clinical practice.

\section{Ethics approval and consent to participate}

Due to the retrospective design of the study, the ethical approval from the institutional review board is exempted.

\section{Consent for publication}

Not applicable.

\section{Availability of data and materials}

The MIMIC-IV and eICU databases can be downloaded from https://physionet.org/content/mimiciv and https://eicu-crd.mit.edu/, respectively. The source code of the reinforcement learning model can be obtained from the authors upon a reasonable request. 


\section{Competing interests}

The authors declare no conflicts of interest.

\section{Funding}

This study was supported by the National Natural Science Foundation of China (31870938, 82070087), and Zhejiang Province Key Research \& Development Program (No. 2020C03073).

\section{Authors' contributions}

QP and HG were responsible for the study concept and design; $Y Z$ and $Y Q$ contributed to the acquisition of data; $\mathrm{QP}, \mathrm{YZ}$ and $\mathrm{YQ}$ contributed to the data analysis and model development; QP, ZZ, LF, GN, LH and HG contributed to the results interpretation; QP and YZ drafted the manuscript; GN, LH and HG substantially revised the manuscript; all the authors read and approved the final manuscript.

\section{Acknowledgements}

Not applicable.

\section{References}

1. Pham T, Rubenfeld GD: Fifty Years of Research in ARDS. The Epidemiology of Acute Respiratory Distress Syndrome. A 50th Birthday Review. Am J Respir Crit Care Med 2017, 195(7):860-870.

2. Sahetya SK, Goligher EC, Brower RG: Fifty Years of Research in ARDS.Setting 
Positive End-Expiratory Pressure in Acute Respiratory Distress Syndrome. Am J Respir Crit Care Med 2017, 195(11):1429-1438.

3. Guo L, Xie J, Huang Y, Pan C, Yang Y, Qiu H, Liu L: Higher PEEP improves outcomes in ARDS patients with clinically objective positive oxygenation response to PEEP: a systematic review and meta-analysis. BMC Anesthesiol 2018, 18(1):172.

4. Brower R, Lanken P, Maclntyre N, Matthay M, Morris A, Ancukiewicz M, Schoenfeld D, Thompson B: Higher versus Lower Positive End-Expiratory Pressures in Patients with the Acute Respiratory Distress Syndrome. N Engl J Med 2004, 351(4):327-336.

5. Goligher EC, Kavanagh BP, Rubenfeld GD, Adhikari NK, Pinto R, Fan E, Brochard LJ, Granton JT, Mercat A, Marie Richard JC et al: Oxygenation response to positive end-expiratory pressure predicts mortality in acute respiratory distress syndrome. A secondary analysis of the LOVS and ExPress trials. Am J Respir Crit Care Med 2014, 190(1):70-76.

6. Zhao Z, Chang MY, Chang MY, Gow CH, Zhang JH, Hsu YL, Frerichs I, Chang $\mathrm{HT}$, Moller K: Positive end-expiratory pressure titration with electrical impedance tomography and pressure-volume curve in severe acute respiratory distress syndrome. Ann Intensive Care 2019, 9(1):7.

7. Sahetya SK, Hager DN, Stephens RS, Needham DM, Brower RG: PEEP Titration to Minimize Driving Pressure in Subjects With ARDS: A Prospective Physiological Study. Respir Care 2020, 65(5):583-589.

8. Pintado MC, de Pablo R, Trascasa M, Milicua JM, Rogero S, Daguerre M, Cambronero JA, Arribas I, Sanchez-Garcia M: Individualized PEEP setting in subjects with ARDS: a randomized controlled pilot study. Respir Care 2013, 58(9):1416-1423.

9. Beitler JR, Sarge T, Banner-Goodspeed VM, Gong MN, Cook D, Novack V, Loring SH, Talmor D, Group EP-S: Effect of Titrating Positive End-Expiratory Pressure (PEEP) With an Esophageal Pressure-Guided Strategy vs an Empirical High PEEP-Fio2 Strategy on Death and Days Free From Mechanical Ventilation Among Patients With Acute Respiratory Distress Syndrome: A Randomized Clinical Trial. JAMA 2019, 321(9):846-857.

10. Talmor D, Sarge T, Malhotra A, O'Donnell CR, Ritz R, Lisbon A, Novack V, Loring SH: Mechanical Ventilation Guided by Esophageal Pressure in Acute Lung Injury. N Engl J Med 2008, 359(20):2095-2104.

11. Sarge T, Baedorf-Kassis E, Banner-Goodspeed V, Novack V, Loring SH, Gong MN, Cook D, Talmor D, Beitler JR: Effect of Esophageal Pressure-guided Positive End-Expiratory Pressure on Survival from Acute Respiratory Distress Syndrome: A Risk-based and Mechanistic Reanalysis of the EPVent-2 Trial. 2021, 204(10):1153-1163.

12. Meade MO, Cook DJ, Guyatt GH, Slutsky AS, Arabi YM, Cooper DJ, Davies AR, Hand LE, Zhou Q, Thabane L et al: Ventilation Strategy Using Low Tidal Volumes, Recruitment Maneuvers, and High Positive End-Expiratory Pressure for Acute Lung Injury and Acute Respiratory Distress Syndrome: A Randomized 
Controlled Trial. JAMA 2008, 299(6):637-645.

13. Writing Group for the Alveolar Recruitment for Acute Respiratory Distress Syndrome Trial I, Cavalcanti AB, Suzumura EA, Laranjeira LN, Paisani DM, Damiani LP, Guimaraes HP, Romano ER, Regenga MM, Taniguchi LNT et al: Effect of Lung Recruitment and Titrated Positive End-Expiratory Pressure (PEEP) vs Low PEEP on Mortality in Patients With Acute Respiratory Distress Syndrome: A Randomized Clinical Trial. JAMA 2017, 318(14):1335-1345.

14. Khan YA, Fan E, Ferguson ND: Precision Medicine and Heterogeneity of Treatment Effect in Therapies for ARDS. Chest 2021.

15. Mamdani M, Slutsky AS: Artificial intelligence in intensive care medicine. Intensive Care Med 2021, 47(2):147-149.

16. Esteva A, Robicquet A, Ramsundar B, Kuleshov V, DePristo M, Chou K, Cui C, Corrado G, Thrun S, Dean J: A guide to deep learning in healthcare. Nat Med 2019, 25(1):24-29.

17. Komorowski M, Celi LA, Badawi O, Gordon AC, Faisal AA: The Artificial Intelligence Clinician learns optimal treatment strategies for sepsis in intensive care. Nat Med 2018, 24(11):1716-1720.

18. Peine A, Hallawa A, Bickenbach J, Dartmann G, Fazlic LB, Schmeink A, Ascheid G, Thiemermann C, Schuppert A, Kindle R et al: Development and validation of a reinforcement learning algorithm to dynamically optimize mechanical ventilation in critical care. NPJ Digit Med 2021, 4(1):32.

19. Johnson A, Bulgarelli L, Pollard T, Horng S, Celi LA, Mark R: MIMIC-IV (version 0.4). In.: PhysioNet; 2020.

20. Pollard TJ, Johnson AEW, Raffa JD, Celi LA, Mark RG, Badawi O: The eICU Collaborative Research Database, a freely available multi-center database for critical care research. Sci Data 2018, 5:180178.

21. Ferguson ND, Fan E, Camporota L, Antonelli M, Anzueto A, Beale R, Brochard $L$, Brower R, Esteban A, Gattinoni $L$ et al: The Berlin definition of ARDS: an expanded rationale, justification, and supplementary material. Intensive Care Med 2012, 38(10):1573-1582.

22. Thompson BT, Chambers RC, Liu KD: Acute Respiratory Distress Syndrome. N Engl J Med 2017, 377(6):562-572.

23. Mnih V, Kavukcuoglu K, Silver D, Rusu AA, Veness J, Bellemare MG, Graves A, Riedmiller M, Fidjeland AK, Ostrovski G et al: Human-level control through deep reinforcement learning. Nature 2015, 518(7540):529-533.

24. Chen T, Guestrin C: XGBoost: A Scalable Tree Boosting System. In: Proceedings of the 22nd ACM SIGKDD International Conference on Knowledge Discovery and Data Mining. San Francisco, California, USA: Association for Computing Machinery; 2016: 785-794.

25. Pettenuzzo T, Boscolo A, De Cassai A, Sella N, Zarantonello F, Persona P, Pasin L, Landoni G, Navalesi P: Higher versus lower positive end-expiratory pressure in patients without acute respiratory distress syndrome: a metaanalysis of randomized controlled trials. Crit Care 2021, 25(1):247.

26. Zhang Z, Zheng B, Liu N, Ge H, Hong Y: Mechanical power normalized to 
predicted body weight as a predictor of mortality in patients with acute respiratory distress syndrome. Intensive Care Med 2019, 45(6):856-864.

27. Calfee CS, Delucchi K, Parsons PE, Thompson BT, Ware LB, Matthay MA: Subphenotypes in acute respiratory distress syndrome: latent class analysis of data from two randomised controlled trials. The Lancet Respiratory Medicine 2014, 2(8):611-620.

28. Fan E, Del Sorbo L, Goligher EC, Hodgson CL, Munshi L, Walkey AJ, Adhikari NKJ, Amato MBP, Branson R, Brower RG et al: An Official American Thoracic Society/European Society of Intensive Care Medicine/Society of Critical Care Medicine Clinical Practice Guideline: Mechanical Ventilation in Adult Patients with Acute Respiratory Distress Syndrome. Am J Respir Crit Care Med 2017, 195(9):1253-1263.

29. De Keulenaer BL, De Waele JJ, Powell B, Malbrain ML: What is normal intraabdominal pressure and how is it affected by positioning, body mass and positive end-expiratory pressure? Intensive Care Med 2009, 35(6):969-976.

30. Papazian L, Aubron C, Brochard L, Chiche JD, Combes A, Dreyfuss D, Forel JM, Guerin C, Jaber S, Mekontso-Dessap A et al: Formal guidelines: management of acute respiratory distress syndrome. Ann Intensive Care 2019, 9(1):69.

31. Villar J, Perez-Mendez L, Kacmarek RM: The Berlin definition met our needs: no. Intensive Care Med 2016, 42(5):648-650.

32. Gattinoni L, Tonetti T, Cressoni M, Cadringher P, Herrmann P, Moerer O, Protti A, Gotti M, Chiurazzi C, Carlesso EJICM: Ventilator-related causes of lung injury: the mechanical power. 2016, 42(10):1567-1575. 
Table 1 Characteristics of the patients at baseline

\begin{tabular}{|c|c|c|c|}
\hline Dataset & MIMIC-IV & elCU & $p$-value \\
\hline Included ARDS patients & 6839 & 2117 & \\
\hline Male sex & $4014(58.7)$ & $1255(59.3)$ & 0.66 \\
\hline Age, years & $62.7( \pm 15.8)$ & $61.0( \pm 16.2)$ & $<0.0001$ \\
\hline \multicolumn{4}{|l|}{ ARDS risk } \\
\hline Direct & $3534(51.7)$ & $1200(56.7)$ & \\
\hline Indirect & $3305(48.3)$ & $917(43.3)$ & \\
\hline \multicolumn{4}{|l|}{ ARDS severity } \\
\hline Mild & $1697(24.8)$ & $404(19.1)$ & \\
\hline Moderate & $4005(58.6)$ & $1002(47.3)$ & \\
\hline Severe & $1137(16.6)$ & $711(33.6)$ & \\
\hline \multicolumn{4}{|l|}{ Mortality } \\
\hline Mild & $299(17.6)$ & $64(15.8)$ & \\
\hline Moderate & $856(21.4)$ & $213(21.3)$ & \\
\hline Severe & $405(35.6)$ & 247 (34.7) & \\
\hline Total & $1560(22.8)$ & $524(24.8)$ & \\
\hline LOS ICU, days & $11.3( \pm 12.3)$ & $9.7( \pm 9.4)$ & $<0.0001$ \\
\hline LOS Hosp, days & $21.3( \pm 30.1)$ & $17.4( \pm 16.0)$ & $<0.0001$ \\
\hline 28-day ventilation-free days & $21.4( \pm 5.8)$ & $17.0( \pm 9.8)$ & $<0.0001$ \\
\hline \multicolumn{4}{|l|}{ Ventilator parameters } \\
\hline PEEP, $\mathrm{cmH}_{2} \mathrm{O}$ & $7.7( \pm 3.6)$ & $6.9( \pm 3.0)$ & $<0.0001$ \\
\hline $\mathrm{FiO}_{2}, \%$ & $45.5( \pm 10.5)$ & $46.0( \pm 14.6)$ & $<0.0001$ \\
\hline Tidal volume, $\mathrm{mL}$ & $460.8( \pm 115.7)$ & $462.2( \pm 93.2)$ & $<0.0001$ \\
\hline$P_{\text {peak }}, \mathrm{cmH}_{2} \mathrm{O}$ & $20.9( \pm 7.4)$ & $23.7( \pm 7.8)$ & $<0.0001$ \\
\hline \multicolumn{4}{|l|}{ Oxygenation } \\
\hline $\mathrm{P} / \mathrm{F}, \mathrm{mmHg}$ & $261.4( \pm 115.4)$ & $229.9( \pm 120.8)$ & $<0.0001$ \\
\hline $\mathrm{SpO}_{2}, \%$ & $96.7( \pm 2.8)$ & $96.2( \pm 3.2)$ & $<0.0001$ \\
\hline $\mathrm{PaO}_{2}, \mathrm{mmHg}$ & $112.7( \pm 42.2)$ & $96.6( \pm 42.0)$ & $<0.0001$ \\
\hline \multicolumn{4}{|l|}{ Respiratory mechanics } \\
\hline $\mathrm{DP}, \mathrm{cmH}_{2} \mathrm{O}$ & $12.7( \pm 5.2)$ & $14.1( \pm 5.3)$ & $<0.0001$ \\
\hline $\mathrm{MP}, \mathrm{J} / \mathrm{min}$ & $13.5( \pm 8.7)$ & $16.1( \pm 9.1)$ & $<0.0001$ \\
\hline \multicolumn{4}{|l|}{$\begin{array}{l}\text { Clinical scores at ICU } \\
\text { admission, points }\end{array}$} \\
\hline SOFA & $8.9( \pm 4.1)$ & $8.9( \pm 3.9)$ & 0.65 \\
\hline
\end{tabular}

Data are mean $( \pm S D)$ or number $(\%)$.

Abbreviations: LOS: Length of stay, PEEP: Positive End-Expiratory Pressure, Ppeak: Peak inspiratory pressure, $\mathrm{P} / \mathrm{F}: \mathrm{PaO}_{2} / \mathrm{FiO}_{2}$ ratio, $\mathrm{SpO}_{2}$ : pulse oximetry, DP: Driving pressure, MP: Mechanical power, SOFA: Sequential organ failure assessment.

$\mathrm{MP}$ was calculated as described previously [32]: MP (J/minutes $)=0.098 \times \mathrm{V}_{\mathrm{T}} \times \mathrm{RR} \times\left(\mathrm{P}_{\text {peak }}-\right.$ $0.5 \times \mathrm{DP})$ 
Table 2 Percentage of the patients where clinicians gave higher, equal, and lower PEEP grades during the first 7 days of MV using assist/control ventilation, and its relationship with the outcome in the MIMIC-IV database. One-fifth of the patients were randomly selected for this analysis because the other four-fifth were used for training the RL model.

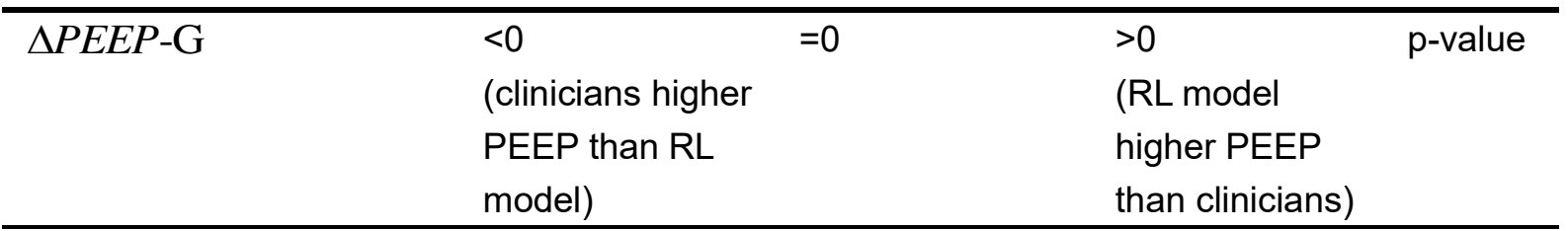

Number of patients

$\mathrm{n}(\%)$

mild ARDS

$86(28.8)$

$137(45.8)$

$76(25.4)$

moderate ARDS

$427(53.4)$

$144(18.0)$

$229(28.6)$

severe ARDS

186 (75.9)

6 (2.4)

$53(21.6)$

total

699 (52.0)

287 (21.4)

358 (26.6)

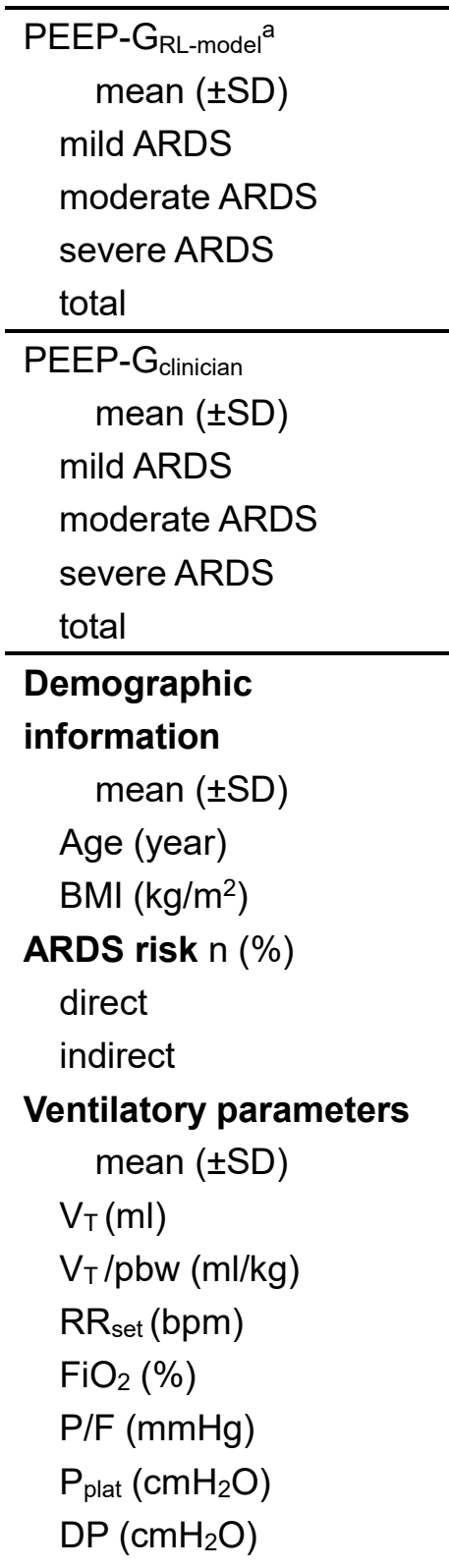

$\begin{array}{llll}64.2( \pm 15.3) & 66.8( \pm 15.6) & 57.6( \pm 15.3) & <0.0001 \\ 30.6( \pm 8.8) & 28.3( \pm 7.1) & 28.4( \pm 6.7) & <0.0001 \\ & & & \\ 411(58.8) & 122(42.5) & 184(51.4) & \\ 288(41.2) & 165(57.4) & 174(48.6) & \\ & & & \\ & & & \\ 447.2( \pm 67.1) & 464.0( \pm 62.5) & 458.1( \pm 68.7) & <0.001 \\ 7.1( \pm 1.1) & 7.6( \pm 1.2) & 7.1( \pm 1.1) & <0.0001 \\ 19.4( \pm 4.7) & 16.0( \pm 2.9) & 19.4( \pm 3.9) & <0.0001 \\ 49.3( \pm 8.9) & 44.2( \pm 6.8) & 47.8( \pm 8.2) & <0.0001 \\ 242.6( \pm 85.3) & 316.5( \pm 120.5) & 258.3( \pm 83.3) & <0.0001 \\ 22.0( \pm 4.3) & 17.6( \pm 3.5) & 19.7( \pm 4.2) & <0.0001 \\ 12.7( \pm 3.4) & 12.6( \pm 3.5) & 13.3( \pm 3.9) & <0.001\end{array}$




\begin{tabular}{|c|c|c|c|c|}
\hline $\mathrm{P}_{\text {peak }}\left(\mathrm{cmH}_{2} \mathrm{O}\right)$ & $25.0( \pm 5.3)$ & $19.4( \pm 4.3)$ & $22.1( \pm 5.2)$ & $<0.01$ \\
\hline $\mathrm{C}_{\mathrm{rs}}\left(\mathrm{ml} / \mathrm{cmH}_{2} \mathrm{O}\right)$ & $41.1( \pm 14.5)$ & $41.3( \pm 13.6)$ & $39.2( \pm 13.1)$ & 0.059 \\
\hline MP (J/minute) & $17.3( \pm 6.8)$ & $10.7( \pm 3.7)$ & $14.3( \pm 4.7)$ & $<0.0001$ \\
\hline norMP $\left(\times 10^{-3} \mathrm{~J} / \mathrm{min} / \mathrm{kg}\right)$ & $273.5( \pm 101.4)$ & $174.6( \pm 64.8)$ & $222.8( \pm 76.7)$ & $<0.0001$ \\
\hline \multicolumn{5}{|l|}{$\begin{array}{l}\text { Clinical scores } \\
\text { mean }( \pm S D)\end{array}$} \\
\hline SOFA & $9.4( \pm 4.1)$ & $7.3( \pm 3.8)$ & $9.8( \pm 4.1)$ & $<0.0001$ \\
\hline \multicolumn{5}{|l|}{ Outcome } \\
\hline \multicolumn{5}{|l|}{ ICU mortality, n (\%) } \\
\hline mild ARDS & $17(19.8)$ & $13(9.5)$ & $9(11.8)$ & \\
\hline moderate ARDS & $85(19.9)$ & $18(12.5)$ & $60(26.2)$ & \\
\hline severe ARDS & $77(41.4)$ & $0(0.0)$ & $16(30.2)$ & \\
\hline total & $179(25.6)$ & $31(10.8)$ & $85(23.7)$ & \\
\hline \multicolumn{5}{|l|}{ 28-day ventilation-free } \\
\hline \multicolumn{5}{|l|}{ days, mean $( \pm S D)$} \\
\hline mild ARDS & $21.9( \pm 6.0)$ & $23.9( \pm 3.8)$ & $22.8( \pm 5.3)$ & $<0.01$ \\
\hline moderate ARDS & $20.4( \pm 5.8)$ & $23.6( \pm 3.8)$ & $21.8( \pm 5.3)$ & $<0.0001$ \\
\hline severe ARDS & $18.7( \pm 7.1)$ & $21.3( \pm 5.5)$ & $19.4( \pm 5.9)$ & 0.578 \\
\hline total & $20.1( \pm 6.2)$ & $23.7( \pm 3.8)$ & $21.6( \pm 5.5)$ & $<0.0001$ \\
\hline
\end{tabular}

a: The actual PEEP range is between $5+($ PEEP grade -1$) \times 2$ and $5+$ PEEP grade $\times$ $2 \mathrm{cmH}_{2} \mathrm{O}$ 
Table 3 Characteristics of the patients in the five groups of $\triangle P E E P-\mathrm{G}$ in the MIMIC-IV database

\begin{tabular}{|c|c|c|c|c|c|c|}
\hline Groups of $\triangle P E E P-\mathrm{G}$ & -2 & -1 & 0 & 1 & 2 & p-value \\
\hline Range of $\triangle P E E P-\mathrm{G}$ & $<-1$ & {$[-1,0)$} & 0 & $(0,1]$ & $>1$ & \\
\hline \multicolumn{7}{|l|}{ No. } \\
\hline Mild & 23 & 63 & 137 & 48 & 28 & \\
\hline Moderate & 211 & 216 & 144 & 130 & 99 & \\
\hline Severe & 116 & 70 & 6 & 37 & 16 & \\
\hline All & 349 & 350 & 287 & 215 & 143 & \\
\hline \multicolumn{7}{|l|}{ Mortality (\%) } \\
\hline Mild & 8.7 & 23.8 & 9.5 & 14.6 & 7.1 & \\
\hline Moderate & 24.8 & 15.2 & 12.5 & 25.4 & 27.3 & \\
\hline Severe & 41.4 & 41.3 & 0.0 & 35.1 & 18.8 & \\
\hline All & 29.2 & 22.0 & 10.8 & 24.7 & 22.4 & \\
\hline \multicolumn{7}{|c|}{ Free from ventilation (days) } \\
\hline Mild & $25.4(23.8,26.4)$ & $23.7(18.7,25.6)$ & $25.3(22.9,26.5)$ & $24.0(19.0,25.9)$ & $25.9(24.1,26.4)$ & $<0.01$ \\
\hline Moderate & $22.0(17.0,25.1)$ & $21.7(16.9,25.1)$ & $25.1(22.5,26.2)$ & $23.2(18.6,25.4)$ & $24.0(20.6,26.1)$ & $<0.0001$ \\
\hline Severe & $19.7(12.4,24.4)$ & $22.1(16.4,24.8)$ & $21.9(21.4,24.5)$ & $19.4(15.1,23.6)$ & $22.1(17.3,24.9)$ & 0.186 \\
\hline All & $21.7(16.3,25.2)$ & $22.3(17.0,25.2)$ & $25.1(22.5,26.3)$ & $23.1(18.1,25.4)$ & $24.7(21.0,26.2)$ & $<0.0001$ \\
\hline \multicolumn{7}{|l|}{ Admission type (No.) } \\
\hline Urgent & $298(85.4)$ & $296(84.6)$ & $251(87.5)$ & $158(73.5)$ & $101(70.6)$ & \\
\hline Non-urgent & $51(14.6)$ & $54(15.4)$ & $36(12.5)$ & $57(26.5)$ & $42(39.4)$ & \\
\hline \multicolumn{7}{|l|}{ ARDS risk (No.) } \\
\hline Direct & $207(59.3)$ & $204(58.3)$ & $122(42.5)$ & $109(50.7)$ & $75(52.4)$ & \\
\hline Indirect & $142(40.6)$ & $146(41.7)$ & 165 & $106(49.3)$ & $68(47.6)$ & \\
\hline Age (year) & $64.0(53.0,74.0)$ & $67.0(57.2,77.7)$ & $68.0(59.0,79.0)$ & $61.0(52.0,70.0)$ & $54.0(45.0,64.5)$ & $<0.0001$ \\
\hline BMI $\left(\mathrm{kg} / \mathrm{m}^{2}\right)$ & $30.5(26.7,35.8)$ & $28.3(23.4,32.2)$ & $27.8(23.1,31.5)$ & $28.4(24.3,31.9)$ & $26.6(23.6,30.5)$ & $<0.0001$ \\
\hline
\end{tabular}




\begin{tabular}{|c|c|c|c|c|c|c|}
\hline PEEP $\left(\mathrm{cmH}_{2} \mathrm{O}\right)$ & $10.5(9.1,12.7)$ & $7.1(6.0,8.8)$ & $5.0(5.0,5.2)$ & $6.4(5.2,8.2)$ & $5.3(5.0,6.2)$ & $<0.0001$ \\
\hline $\mathrm{V}_{\mathrm{T}}(\mathrm{ml})$ & $450.0(400.0,499.7)$ & $450.0(400.6,500.0)$ & $460.3(419.0,500.0)$ & $453.1(414.8,500.0)$ & $458.6(418.5,500.3)$ & $<0.01$ \\
\hline $\mathrm{V}_{\mathrm{T}} / \mathrm{pbw}(\mathrm{ml} / \mathrm{kg})$ & $6.9(6.3,7.6)$ & $7.1(6.4,7.7)$ & $7.4(6.7,8.1)$ & $7.1(6.5,7.7)$ & $6.9(6.3,7.7)$ & $<0.0001$ \\
\hline $\mathbf{R R}_{\text {set }}$ (bpm) & $20.0(16.3,23.8)$ & $18.0(15.4,20.4)$ & $16.0(14.0,18.0)$ & $18.5(16.0,21.4)$ & $19.8(17.3,22.0)$ & $<0.0001$ \\
\hline $\mathrm{FiO}_{2}(\%)$ & $50.0(44.9,56.1)$ & $46.8(41.4,51.4)$ & $42.6(40.0,50.0)$ & $47.6(41.7,53.4)$ & $47.8(41.3,50.0)$ & $<0.0001$ \\
\hline $\mathrm{P} / \mathrm{F}$ (mmHg) & $221.7(171.0,274.0)$ & $244.0(195.0,307.6)$ & $298.7(238.1,363.8)$ & $250.8(199.3,299.8)$ & $243.5(202.9,310.5)$ & $<0.0001$ \\
\hline$P_{\text {plat }}\left(\mathrm{cmH}_{2} \mathrm{O}\right)$ & $23.4(20.7,26.1)$ & $20.1(17.6,22.9)$ & $17.1(15.0,19.3)$ & $19.8(17.3,22.7)$ & $18.9(16.0,21.2)$ & $<0.0001$ \\
\hline $\mathrm{DP}\left(\mathrm{cmH}_{2} \mathrm{O}\right)$ & $12.2(10.2,14.5)$ & $12.6(10.4,15.0)$ & $12.1(10.2,14.2)$ & $12.6(10.4,15.3)$ & $13.1(10.7,15.8)$ & $<0.01$ \\
\hline $\mathrm{C}_{\mathrm{rs}}\left(\mathrm{ml} / \mathrm{cmH}_{2} \mathrm{O}\right)$ & $39.7(31.4,48.5)$ & $37.7(30.7,47.3)$ & $39.1(32.3,47.9)$ & $37.0(31.1,45.8)$ & $37.9(30.9,45.9)$ & 0.051 \\
\hline$P_{\text {peak }}\left(\mathrm{cmH}_{2} \mathrm{O}\right)$ & $26.6(23.5,30.2)$ & $22.9(19.8,26.2)$ & $19.2(16.3,22.1)$ & $22.5(18.8,25.9)$ & $21.1(17.8,24.4)$ & $<0.0001$ \\
\hline MP (J/minute) & $18.7(14.7,23.3)$ & $14.3(11.1,17.5)$ & $10.3(8.2,12.6)$ & $14.5(11.3,17.4)$ & $13.4(11.0,16.2)$ & $<0.0001$ \\
\hline norMP $\left(\times 10^{-3} \mathrm{~J} / \mathrm{min} / \mathrm{kg}\right)$ & $290.3(237.2,366.2)$ & $230.3(185.8,274.3)$ & $167.4(135.8,203.1)$ & $223.0(166.1,282.7)$ & $208.4(156.6,250.3)$ & $<0.0001$ \\
\hline SOFA & $9.0(6.0,13.0)$ & $9.0(6.0,12.0)$ & $7.0(4.0,10.0)$ & $10.0(6.5,13.0)$ & $10.0(7.0,13.0)$ & $<0.0001$ \\
\hline
\end{tabular}

Data are given in median (IQR).

Mechanical power $(\mathrm{MP})$ was calculated as $\mathrm{MP}(\mathrm{J} / \mathrm{min})=0.098 \times \mathrm{V}_{\mathrm{T}} \times \mathrm{RR} \times\left(\mathrm{P}_{\text {peak }}-0.5 \times \mathrm{DP}\right)$ [32].

Normalized mechanical power (norMP) was calculated as norMP $\left(\times 10^{-3} \mathrm{~J} / \mathrm{min} / \mathrm{kg}\right)=\mathrm{MP} / \mathrm{PBW}$ [26]. 


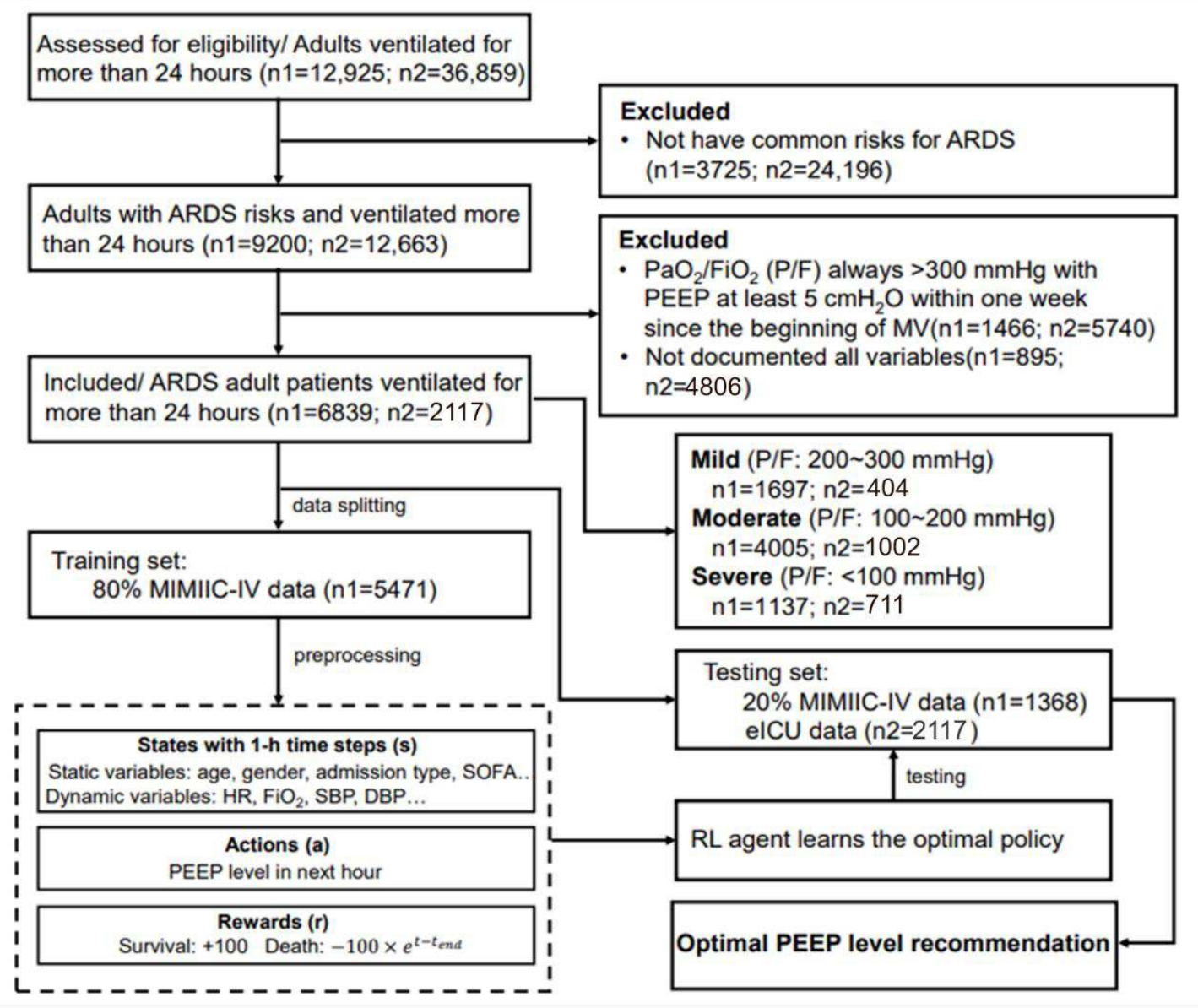

Figure 1 Flow diagram of the study. n1: numbers in MIMIC-IV database, n2: numbers in eICU database. 


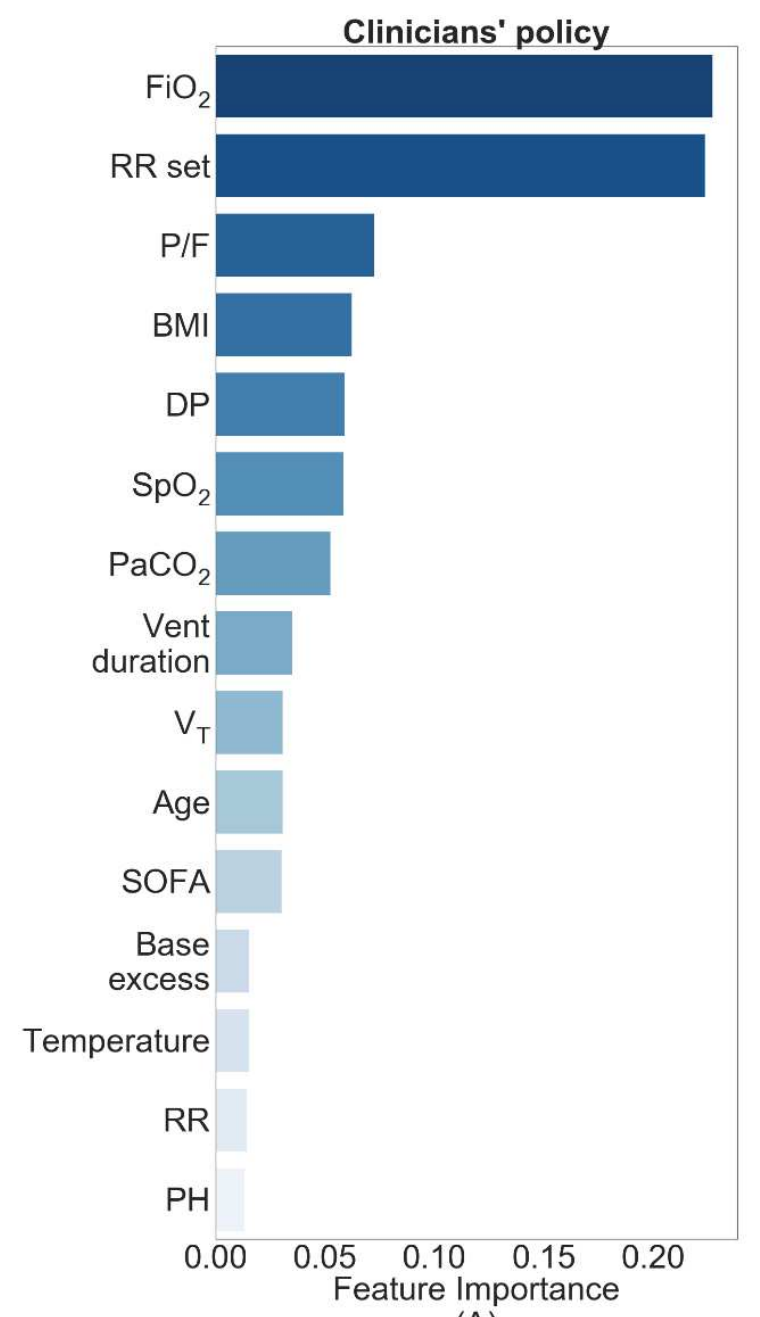

(A)

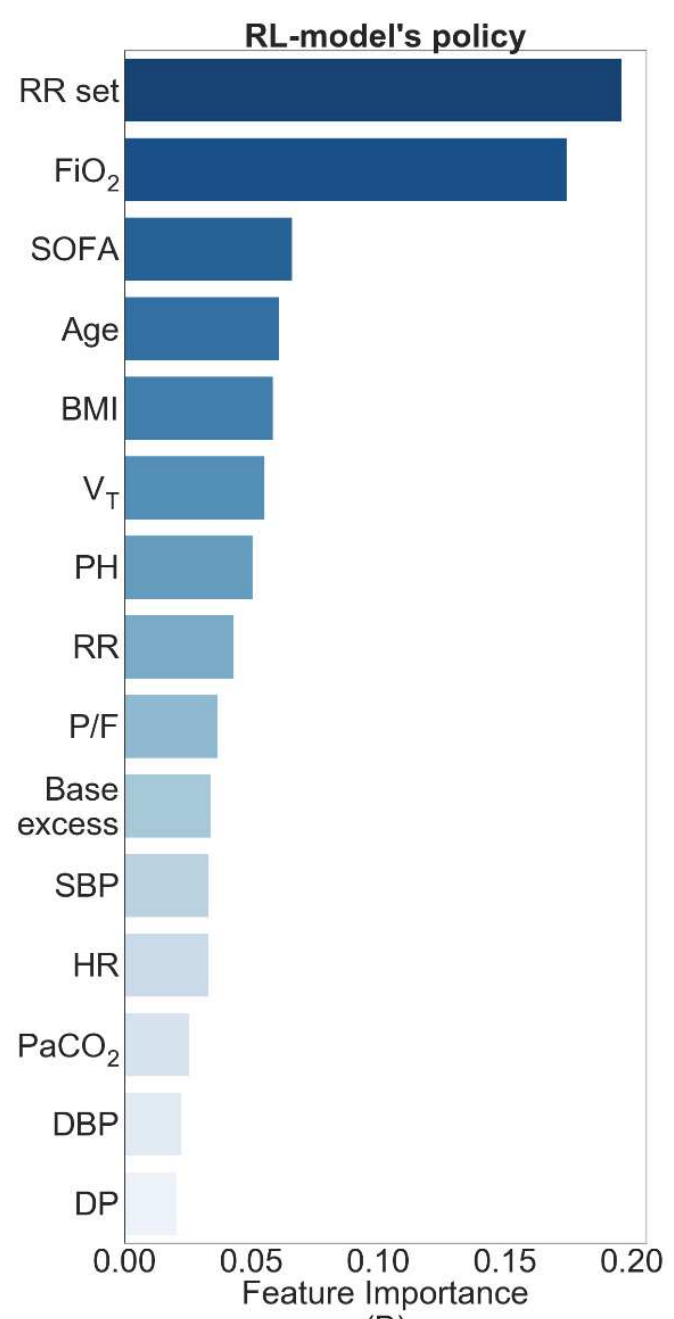

(B)

Figure 2 Ranking of relative feature importance of the $(A)$ clinicians and $(B) R L$ model for high PEEP $\left(\geq 10 \mathrm{cmH}_{2} \mathrm{O}\right)$ and low PEEP $\left(<10 \mathrm{cmH}_{2} \mathrm{O}\right)$ in MIMIC-IV database. Abbreviations: RR set: ventilatory respiration rate setting. $\mathrm{P} / \mathrm{F}: \mathrm{PaO}_{2} / \mathrm{FiO}_{2}$ ratio. $\mathrm{BMI}$ : body mass index. DP: driving pressure. $\mathrm{V}_{\mathrm{T}}$ : tidal volume. SOFA: Sequential Organ Failure Assessment. RR: respiration rate (from monitors). SBP: systolic blood pressure. DBP: diastolic blood pressure. 


\section{Supplementary Files}

This is a list of supplementary files associated with this preprint. Click to download.

- ESM20220203CC.docx 